\title{
Unconventional biomass fuels for steam gasification: kinetic analysis and effect of ash composition on reactivity
}

M.P. González-Vázquez, R. García, M.V. Gil, C. Pevida*, F. Rubiera

Instituto Nacional del Carbón, INCAR-CSIC, c/ Francisco Pintado Fe 26, 33011 Oviedo, Spain

\begin{abstract}
Twelve commercial and unconventional biomass fuels were evaluated in steam gasification; these include samples of hard biomass (wood, almond, olive and pine kernel wastes) and soft biomass (miscanthus, switchgrass, coffee, cocoa and grape wastes). Gasification tests at $700-1000{ }^{\circ} \mathrm{C}$ of biomass chars obtained from a bubbling fluidized bed reactor were performed in a TG analyzer. Steam gasification kinetics were extensively analyzed: an index of key parameters for the twelve biomasses and the correlation to biomass ash composition were developed. The random pore model (RPM) described the experimental reactivity best, with activation energies of 59-196 kJ mol${ }^{-1}$. The study of their reactivities provided a ranking of fast-, medium- and slow-kinetics fuels. The influence of alkaline and alkaline-earth metals (AAEM) on reactivity revealed that $\mathrm{K}, \mathrm{Na}$ and $\mathrm{Mg}$ had a positive effect while $\mathrm{Si}, \mathrm{P}$ and $\mathrm{Ca}$ had a negative influence.
\end{abstract}

Keywords: Biomass; Steam gasification; TGA; Kinetic parameters; Ash inorganic elements

\footnotetext{
* Corresponding author. Tel.: +34 9851189 87; Fax: +34 985297662

E-mail address: cpevida@incar.csic.es (C. Pevida)
} 


\section{Introduction}

Biomass is, after oil, coal and natural gas, one of the most widely consumed energy resources. It is also considered as a valid complement to traditional fossil fuels since it is neutral with regards to the emission of carbon dioxide. Gasification is one of the most interesting energy conversion techniques; it is a versatile thermochemical process that consists in the partial oxidation at high temperatures of the organic matter of a selected liquid or solid fuel (coal, raw and torrefied biomass, alternative wastes such as plastics or municipal solid wastes, or their mixtures) to obtain a variety of primary (syngas, charcoal, heat, tars) or secondary (electricity, biodiesel, chemicals) products [1]. Different types of reactors have been proposed to carry out gasification, the most common of which are fixed-bed, fluidized-bed or entrained flow reactors, though plasma reactors and rotary kilns are also used [2]. Gasification can also be performed over a broad range of temperatures $\left(600-1500{ }^{\circ} \mathrm{C}\right)$ [3] and pressures (1-10 bar) [4], using different oxidizing agents (air, $\mathrm{O}_{2}, \mathrm{CO}_{2}$, steam, or their mixtures) [5], which clearly influence the composition of the final product.

Traditionally this reaction was used to produce a highly calorific stream of syngas, with a variable composition of $\mathrm{CO}, \mathrm{H}_{2}, \mathrm{CH}_{4}$ and $\mathrm{CO}_{2}$ by means of the partial oxidation of the selected fuel in an impoverished $\mathrm{O}_{2}$, air or $\mathrm{CO}_{2}$ atmosphere. Recent concerns that are focused on the development of a cleaner and more sustainable production of $\mathrm{H}_{2}$, have directed attention towards the $\mathrm{N}_{2}$-steam or air-steam gasification of biomass, which offers the additional advantage of obtaining an easily manageable, high thermal power gaseous flow from a low density solid waste [6].

There are many different types of biomass resources. For this reason a good knowledge of the gasification process for the different available biomass fuels is necessary to be 
able to predict experimental performance and to be in a position to develop large-scale systems. More specifically, a knowledge of char reactivity and kinetics for different biomass samples is essential for designing and modelling gasification at industrial scale. From the mass loss experimentally obtained by thermogravimetric analysis (TGA), it is possible to derive the kinetic parameters following two different approaches: firstly, the model free or integral iso-conversional methods, the FWO (Flynn-Wall-Ozawa) and KAS (Kissinger-Akahira-Sunose) [7,8] being the most commonly used; and secondly, the model-based methods, which can be divided into those that are isothermal, when mass loss is obtained at constant temperature, and those that are non-isothermal, if the constant parameter is the heating rate $(\beta)$ [9].

Several works have been undertaken to study the kinetic behavior of raw and blended biomass gasification under different conditions. Thus, Mabuda et al. [10] used Kissinger and FWO model-free methods to determine the kinetic parameters for the steam gasification of pine wood mixed with $\mathrm{CO}_{2}$ adsorbents $(\mathrm{CaO}$ and $\mathrm{MgO})$, in a temperature range from 20 to $900{ }^{\circ} \mathrm{C}$, at heating rates of 10,15 and $20^{\circ} \mathrm{C} \mathrm{min}-1$, and obtained activation energy $\left(E_{a}\right)$ values of around $140 \mathrm{~kJ} \mathrm{~mol}^{-1}$. Fermoso et al. [11] used nonisothermal TGA methods to study the steam gasification behavior and to obtain the kinetic parameters of chestnut wastes, olive stones and their blends with a bituminous coal from room temperature to $1100{ }^{\circ} \mathrm{C}$ at heating rates of 5,10 and $15{ }^{\circ} \mathrm{C} \min ^{-1}$. Three nth-order representative gas-solid models, the volumetric model (VM), the grain model (GM) and the random pore model (RPM), were used to describe the reactive behavior of the chars during steam gasification in that study. The best model for describing the reactivity of the coal/biomass blends was the RPM model $\left(E_{a}=257-261 \mathrm{~kJ} \mathrm{~mol}^{-1}\right)$, whereas the VM was the model that best suited the chestnut wastes sample $\left(E_{a}=259 \mathrm{~kJ}\right.$ 
$\mathrm{mol}^{-1}$ ). On the other hand, none of the models were found to be suitable for the olive stones sample.

Using isothermal methods, Fermoso et al. [4] studied the effect of the pressure and the oxidizer concentration during $\mathrm{CO}_{2}$ gasification of slash pine chars obtained at different temperatures. The authors determined the kinetic parameters $\left(E_{a}=145-246 \mathrm{~kJ} \mathrm{~mol}^{-1}\right)$ and tested the predictive behavior of the VM, GM and RPM nth-order kinetic models under isothermal conditions at different temperatures $\left(750-900{ }^{\circ} \mathrm{C}\right)$. A good prediction for the conversion of the chars was achieved with the three models at atmospheric pressure, while only the RPM model achieved a good fitting at 10 bar. Le and Kolaczkowski [12] used the VM and GM models to obtain the isothermal kinetic parameters of refuse-derived fuel (RDF) char gasification $\left(800-900{ }^{\circ} \mathrm{C}\right)$ in a steam- $\mathrm{N}_{2}$ mixture using a packed bed tubular reactor, and they found that the two models produced very similar results across the range of conditions tested $\left(E_{a}=96-162 \mathrm{~kJ}\right.$ $\mathrm{mol}^{-1}$ ). Similar conditions were used by Zhai et al. [13] to study the kinetic behavior of rice-husk char steam gasification, and they concluded that the surface reaction controlled GM model best described the steam gasification reaction of rice-husk char at temperatures lower than $850{ }^{\circ} \mathrm{C}$, and that gas diffusion controlled the overall reaction at temperatures higher than $850{ }^{\circ} \mathrm{C}$. These authors obtained $E_{a}$ values of $53-75 \mathrm{~kJ} \mathrm{~mol}^{-1}$. From the literature, it can be concluded that very different kinetic results are obtained for different biomass resources under variable experimental conditions. However, the variability in the reported results is probably caused not only by the variable properties of the biomass, but also by the different pyrolysis conditions, gasification conditions (temperature, gasifying agent concentration) and the type of reactor used, making it difficult to draw comparisons between biomasses. In the present work, therefore, 12 
biomass samples of different characteristics and origin, including woody and herbaceous biomass, forest or food industry wastes, as well as energy crops, have been analyzed under similar conditions in order to obtain comparable results and establish possible relationships between the reactivity results and the biomass characteristics. To the best of our knowledge this has been scarcely reported in literature $[14,15]$.

Due to the limited and seasonal availability of biomass, the gasifiers will need to cope with a variety of feedstocks, derived from different species of variable nature. Thus, the aim of this work was to develop a database containing the main kinetic parameters, Arrhenius pre-exponential factor $\left(k_{0}\right)$ and activation energy $\left(E_{a}\right)$, for the steam gasification of several selected alternative biomass chars. The kinetic analysis was performed at temperatures between 700 and $1000{ }^{\circ} \mathrm{C}$, using the VM, GM and RPM model-based isothermal methods. Additional studies were also carried out to reinforce the kinetic study. These included a study of the reactivity of the chars based on the TG results, the autocatalytic effect produced by the alkali $(\mathrm{Na}, \mathrm{K})$ and the earth-alkali $(\mathrm{Ca}$, $\mathrm{Mg}$ ) metals present in the biomass ash, and the gasification inhibition produced by $\mathrm{Si}$ and P. Finally, the effect of the steam concentration was evaluated.

\section{Materials and methods}

\subsection{Samples and char preparation}

Twelve lignocellulosic biomass samples (almond shell - AS-, coffee dregs - CD-, coffee husk $-\mathrm{CH}-$, chestnut sawdust $-\mathrm{CHE}-$, cocoa shell $-\mathrm{CS}-$, grape pomace $-\mathrm{GP}-$, miscanthus -MIS-, olive stone-OS-, pine cone leaf -PCL-, torrefied pine sawdust PINT-, pine kernel shell -PKS- and switchgrass -SG-) from different origins were 
selected to determine their kinetic behavior during steam gasification. Pictures of the raw biomasses are presented in Fig. 1.

The samples were ground using a Retsch SM 2000 cutting mill and sieved to a particle size of $0.425-1 \mathrm{~mm}$. The proximate, ultimate and heating value analyses of the raw biomass samples are shown in Table 1. Oxygen and fixed carbon (FC) contents were obtained by difference, by means of Eq. (1) [15] and Eq. (2) [16], respectively.

$\mathrm{O}(\%)=100-($ Ash $+\mathrm{C}+\mathrm{N}+\mathrm{H}+\mathrm{S})$

$\mathrm{FC}(\%)=100-(\mathrm{VM}+\mathrm{Ash})$

where VM is the volatile matter content.

In addition, the ash elemental composition of the samples, expressed as metallic oxides, was determined by X-Ray fluorescence (XRF) in a SRS 3000 Bruker XRF spectrometer. The obtained results are given in Table 2.

To prepare the chars, a representative sample of biomass was obtained using a riffle. Thus, $1 \mathrm{~g}$ of each biomass sample was pyrolyzed at $1000{ }^{\circ} \mathrm{C}$ under an inert atmosphere in a $52 \mathrm{~mm}$ internal diameter bench-scale fluidized bed reactor. Silica sand was employed as bed material and nitrogen $\left(1.365 \mathrm{~L} \mathrm{~min}^{-1}\right)$ was used as the fluidizing gas. A basket made of steel wire mesh was used to retrieve the pyrolyzed chars from the reactor, while nitrogen was injected at room temperature to avoid the oxidation of the chars. Additional details can be found elsewhere [17] (Arenillas et al., 2005). The pyrolyzed chars were milled in a Retsch MM 200 ball mill to obtain a particle size below $100 \mu \mathrm{m}$.

\subsection{Gasification experiments}


Gasification kinetic tests were conducted by TGA, using a Setaram TAG24 analyzer (detection limit of $0.0002 \mathrm{mg}$ ). TGA is one of the most common techniques used to assess thermal behavior and kinetics during the combustion and gasification of solid raw materials, such as biomass. It measures the mass loss of a sample as a function of time and temperature, so quantitative methods can be applied to TGA curves to obtain the kinetic parameters of thermal events by applying the Arrhenius equation. For each TGA run a mass of approximately $5 \mathrm{mg}$ of char sample was deposited in a platinum crucible (height $=2 \mathrm{~mm}$, diameter $=6 \mathrm{~mm}$ ) and subjected to controlled isothermal $\mathrm{N}_{2-}$ steam gasification $\left(75 / 25\right.$ vol. $\left.\% \mathrm{~N}_{2} / \mathrm{H}_{2} \mathrm{O}\right)$. A thermocouple was placed close to the platinum basket to monitor temperature and to close the oven control loop. Gasification tests were performed at intervals of $50{ }^{\circ} \mathrm{C}$ from 700 to $1000{ }^{\circ} \mathrm{C}$, at atmospheric pressure, for each char sample. These temperatures were chosen in order to avoid diffusion problems ensuring kinetic control of the reaction, and consequently to apply the Arrhenius plot for calculating the kinetic parameters. A small amount of sample and a slow heating rate were used to avoid heat transfer limitations and to minimize mass transfer effects. A flow of $100 \mathrm{~mL} \mathrm{~min}^{-1}$ of $\mathrm{N}_{2}$ was used as carrier gas, while the required amount of steam was measured as liquid water and supplied by a Bronkhorst $\mathrm{CEM}^{\circledR}$ (Controlled Evaporator and Mixer) device heated at $150{ }^{\circ} \mathrm{C}$. Liquid and mass flow controllers were used to control the flow rates of water and nitrogen in order to ensure that the desired steam concentration remained constant. The sample was allowed to react until completion. Duplicate experiments for each test were performed in order to test the reproducibility of the results (maximum error of $0.001 \mathrm{mg}$ ). Char conversion $(X)$ was calculated from the mass loss obtained during the TGA experiments [18], as indicated by Eq. (3): 
$X=\frac{m_{0}-m_{i}}{m_{0}-m_{a s h}}$

where $m_{0}, m_{\mathrm{i}}$ and $m_{a s h}$ are the initial mass, the mass at time $i$ and the final ash mass remaining at the end of the TGA test, respectively.

In addition, to study the effect of the steam concentration on reactivity and calculate the reaction order with respect to the steam partial pressure, additional gasification tests were carried out under different steam concentrations (10-50 vol.\%) at atmospheric pressure and a fixed temperature of $900{ }^{\circ} \mathrm{C}$ for selected chars, which were representative of fast-, medium- and slow-kinetics samples (CS, SG and CHE, respectively).

\subsection{Kinetic models}

Three different $n$ th-order models were applied in this work in order to describe the gasification rate variation under a steam atmosphere at different temperatures. In this way the characteristic kinetic parameters were determined from TGA mass loss data. The overall kinetics of the gasification process [19], is expressed by Eq. (4):

$\frac{\mathrm{d} X}{\mathrm{~d} t}=k\left(C_{g}, T\right) \cdot f(X)$

where $k$ is the apparent gasification rate as a function of the oxidizing agent concentration $\left(C_{g}\right)$ and the temperature $(T)$, and $f(X)$ is a function of the char conversion, $X$. If the concentration of the oxidizing agent remains constant during the process, which is achieved in the present work in all of the experiments, the apparent gasification rate will depend on the temperature and can be expressed as an Arrhenius equation (Eq. 5):

$k=k_{0} \cdot e^{-E_{a} / R \cdot T}$

This equation relates the reaction rate, $k$, to the temperature, $T$, by means of two constants, characteristic of each studied sample: $k_{0}$ or the pre-exponential factor, which 
is related to the collision of molecules, and $E_{a}$ or activation energy, which can be defined as the minimum energy that is required to begin a chemical reaction. $R$ is the ideal gas constant.

The $n t h$-order kinetic models utilized in this work to describe the reactivity of the chars are the volumetric model (VM), the grain model (GM) and the random pore model $(\mathrm{RPM})$

The volumetric model or uniform reaction model, whose reaction rate is expressed by Eq. (6), assumes a homogeneous reaction across the particle and a reactive surface that decreases linearly with conversion [20].

$\frac{\mathrm{d} X}{\mathrm{~d} t}=k_{\mathrm{VM}} \cdot(1-X)$

Szekely and Evans' grain model, also known as shrinking core model, assumes that the reaction takes place on the surface of a series of spherical, non-porous grains, that join to form a porous particle [21]. The grain's surface, and hence the reaction rate, decrease as the reaction proceeds. The overall reaction rate for this model can be expressed by Eq. (7):

$\frac{\mathrm{d} X}{\mathrm{~d} t}=k_{\mathrm{GM}} \cdot(1-X)^{2 / 3}$

The random pore model (RPM) assumes that the reaction area is limited due to superimposed pore surfaces, and attempts to describe the change in the structure of the pores during char conversion [22]. This model predicts a maximum in the reactivity as the reaction proceeds. The reaction rate equation for this model, Eq. (8), includes a parameter, $\Psi$, related to the pore structure of the initial sample, which can be calculated by Eq. (9), from the morphology of the solid particle ( $L_{0}$ : pore length; $S_{0}$ : pore surface area; $\varepsilon_{0}$ : solid porosity) or from the experimentally calculated conversion at the maximum reaction rate $\left(X_{\max }\right)[23]$ : 
$\frac{\mathrm{d} X}{\mathrm{~d} t}=k_{\mathrm{RPM}} \cdot(1-X) \cdot \sqrt{[1-\Psi \cdot \ln (1-X)]}$

$$
\Psi=\frac{4 \cdot \pi \cdot L_{0} \cdot\left(1-\varepsilon_{0}\right)}{S_{0}^{2}}=\frac{2}{\left[2 \cdot \ln \left(1-X_{\max }\right)+1\right]}
$$

The $\Psi$ parameter is used as a fitting value by some authors [4,23], hence a mathematical adjustment is made for RPM.

The variables in Eqs. (6), (7) and (8) can be separated and integrated in order to be linearized, as shown in Eqs. (10), (11) and (12), respectively, and in this way the kinetic parameters for VM, GM and RPM can be obtained [4].

$-\ln (1-X)=k_{\mathrm{VM}} \cdot t$

$3 \cdot\left[1-(1-X)^{1 / 3}\right]=k_{\mathrm{GM}} \cdot t$

$(2 / \Psi) \cdot\left[\sqrt{[1-\Psi \cdot \ln (1-X)]}-1=k_{\mathrm{RPM}} \cdot t\right.$

The reaction rate constant $\left(k_{i, T}\right.$, where $i=\mathrm{VM}, \mathrm{GM}$ and $\left.\mathrm{RPM}\right)$ for each model under each experimental condition can be calculated from the slope of the straight line in the plots of the linearized expressions. Conversion values in the range of 10-90\% were used for the calculations. The Arrhenius plot (lnk vs. 1/T) was then employed to calculate the activation energy, $E_{a}$, and the pre-exponential factor, $k_{0}$, for each char sample and model.

The deviation, $\operatorname{Dev}(X)$, between the experimentally obtained conversion data and the values predicted by the models was percent-wise measured by means of Eq. (13) [24]:

$\operatorname{Dev}(X)(\%)=\frac{\sqrt{\frac{\sum_{i=1}^{n}\left(X_{\text {exp }}-X_{\text {mod }}\right)^{2}}{n}}}{X_{\text {exp }, \max }} \cdot 100$

where $n$ is the number of data points considered, $X_{\exp }$ and $X_{m o d}$ are the experimentally obtained and model calculated values for $X$, respectively, and $X_{\text {exp }}$ max is the maximum $X_{\text {exp }}$ 


\section{Results and discussion}

\subsection{Kinetic parameters}

The application of the VM, GM and RPM models to the experimental data obtained from the gasification tests at different temperatures is shown, as an example, for several samples in Fig. 2 (samples AS and OS) and Fig. 3 (samples PCL and PKS). From these plots, the reaction rate constants for the different temperatures were determined and, then, represented in Arrhenius plots -lnk vs. 1/T-. As an example, the Arrhenius plots using the VM, GM and RPM models for the AS, OS, PCL and PKS samples are shown in Fig. 4. As can be seen, the data satisfactorily fit to a straight line over the temperature range considered. From these plots, the pre-exponential factor $\left(k_{0}\right)$ and the activation energy $\left(E_{\mathrm{a}}\right)$, as the exponent of the y-coordinate and the slope of the Arrhenius plot, respectively, can be obtained. It must be emphasized that this method of calculation is only valid for the chemically controlled reaction regime, indicated by a change in the slope of the Arrhenius plot. In the present work, the range of temperatures where this occurs varies for the different samples, but is always between 750 and $1000{ }^{\circ} \mathrm{C}$. Figs. 2 and 3 show for each sample, the data of the temperatures where this condition is fulfilled.

The kinetic parameters $\left(E_{a}, k_{0}\right.$ and the $\Psi$ parameter required for RPM) and the values for the deviation between the experimental conversion data and those predicted by the models $(\operatorname{Dev}(X))$ are summarized in Table 3 for the three kinetic models. In the case of the RPM model, the $\Psi$ parameter was calculated in the two ways mentioned above: from the experimental $X_{\max }$ value ( $\left.\Psi_{\text {exp }}\right)$ by means of Eq. (9) and, secondly, as a model fitting parameter using a commercial spreadsheet tool $\left(\Psi_{a d j}\right)$. The resulting kinetic 
parameters $\left(E_{a}, k_{0}\right)$ obtained by using these two approaches are also shown in Table 3. In general, there are notable differences between $\Psi_{\exp }$ and $\Psi_{a d j}$, which does not mean that there is any significant change in the $E_{a}$ values. It signifies there is an improvement in the model fitting when $\Psi_{a d j}$ is used (lower $\operatorname{Dev}(X)$ values).

As Table 3 shows, the $E_{a}$ values extend over a wide range between $57 \mathrm{~kJ} \mathrm{~mol}^{-1}$ (sample CD) and $196 \mathrm{~kJ} \mathrm{~mol}^{-1}$ (sample OS). The $k_{0}$ value also experiences a wide variation between samples. These data confirm the presupposed differences in reactivity, and hence reaction velocity, between the different biomass samples, which will have a direct bearing on the design of the equipment and operation in the gasification process. The parameters obtained fall inside the wide range of values (53-259 $\mathrm{kJ} \mathrm{mol}^{-1}$ ) reported in the literature for biomass fuels [4,10,11,13,23,25]. Morin et al. [26] recently compiled the data from a number of studies on biomass gasification and found activation energy values ranging from 66.5 to $237.0 \mathrm{~kJ} \mathrm{~mol}^{-1}$. However, the dispersion of the values they obtained from different studies will have been caused by the influence of many different variables, such as properties of the biomass, pyrolysis conditions, gasification conditions (temperature range, oxidizing agent concentration) or type of reactor used. In the present work, where the kinetic parameters were obtained under the same conditions for different biomass types, a wide range of values for the kinetic parameters was also detected, which would suggest that the intrinsic biomass characteristics influenced their reactive behavior.

From Table 3, it can also be seen that the $E_{a}$ values are similar for the three models and that the main differences are related to the pre-exponential factor, $k_{0}$. The $E_{a}, k_{0}$ and $\Psi_{a d j}$ values obtained were used to develop predictive models for $X$, based on the VM, GM and RPM equations (Eqs. 10-12). As an example, a graphical comparison of the 
experimental conversion data and the values predicted by the VM, GM and RPM models at the studied temperatures for the AS, OS, PCL and PKS samples are presented in Fig. 5 ( $\mathrm{a}, \mathrm{b}, \mathrm{c}$ and d, respectively). In general, the highest divergences between the experimental and modelled results occur at high conversion values $(X>70 \%)$.

To quantify the errors produced by each model, the $\operatorname{Dev}(X)$ value was calculated by Eq. (13) for the studied temperatures, and the average value for each sample is shown in Table 3. The RPM model which uses $\Psi_{\text {adj }}$ gives the lowest error when predicting conversion during the gasification process for all the biomass samples studied. In the case of samples CHE, PCL and PINT, the $\operatorname{Dev}(X)$ value is very close in the VM and $\mathrm{RPM} \Psi_{a d j}$ models. When the $\Psi$ parameter approaches zero, as in the case of these samples, the RPM model predicts an almost constant decrease in the gasification rate, or reactivity, with conversion, like the VM model, which assumes a homogeneous reaction throughout the particle [20]. However, as $\Psi$ increases, the maximum reaction rate shifts to higher conversions.

\subsection{Reactivity and catalytic/inhibiting effects}

Fig. 5(e) shows a graphical comparison between the experimentally obtained $X$ values for all the tested samples and those predicted by $\mathrm{RPM}_{\Psi_{a d j}}$ at $900{ }^{\circ} \mathrm{C}$, a temperature characteristic of large-scale applications in the biomass gasification process, where the reaction rate between the studied samples can be compared. From these data, reactivity, a key parameter when studying biomass gasification kinetics, can be calculated. To compare the gasification reactivity of the different biomasses studied in the present work, the reactivity index at $900{ }^{\circ} \mathrm{C}(R)$ has been calculated as follows [27]:

$R=\frac{0.5}{t_{0.5}}$ 
where $t_{0.5}$ represents the time required to reach $50 \%$ of char conversion. This index provides information about the reactivity of a sample at a given temperature, and the higher the $R$ values are, the more reactive a sample is.

Fig. 6(a) shows the values of the $R$ index at $900{ }^{\circ} \mathrm{C}$ for all the studied samples, so that their reactivities can be compared. As can be seen, the samples can be distributed into 5 reactivity groups: fast $(\mathrm{CD}, \mathrm{CS})$, medium-fast $(\mathrm{CH}, \mathrm{PINT}, \mathrm{GP})$, medium (OS, PCL, SG), slow-medium (AS, CHE) and slow (MIS, PKS). There are huge differences between the samples, with CD presenting nearly a 40 times higher reactivity than the MIS and PKS samples. When compared with $\mathrm{CH}$, which belongs to the medium-fast reactivity group, the reactivity is 7 times higher. These results must be taken into account when selecting the most adequate fuel for gasification experiments under specific conditions and especially when making mixtures of them.

A direct relationship between the values of $E_{a}$ or $k_{0}$ obtained and the reactivity index has not been found, although there is a clear connection between the reaction rate $k$, calculated by means of Eq. (5) from the kinetic parameters, and the reactivity values. On the other hand, the samples with the highest reactivity (CH, PINT, GP, CS and CD) also present the highest errors ( $>4 \%$ ) when they are fitted to the RPM model (Table 3 ). López-González et al. [28] suggested that the inaccuracy of standard models (VM, GM and RPM) in reproducing the reaction rate, which is here represented by $\operatorname{Dev}(X)$, could be caused by the contribution of ashes to the process.

Samples MIS and PKS showed very low reactivity compared with the rest of the samples. Samples AS, CHE, OS and PCL, with slightly higher reactivities, can be considered woody biomasses, and they are characterized by low ash contents (0.3-1.5 wt.\%) (Table 1). Sample SG is a perennial crop and, like $\mathrm{CH}$, shows intermediate 
reactivity and a medium ash content of 4.2-4.6 wt.\%. Samples GP, CS and CD, with the highest reactivity values, are wastes that have higher ash contents (7.9-12.7 wt.\%). Finally, although pine is also a woody biomass, the PINT sample is really a torrefied pine sawdust, and an increase in the reactivity can be expected after the torrefaction process. Zhang et al. [29] concluded that a torrefaction pretreatment may facilitate the retention of catalytic elements in the solid products since torrefied chars were found to be richer in these elements than their original samples. These species can then play catalytic roles in the subsequent char gasification, explaining why the torrefied biochars were more reactive than the original ones. On the other hand, Guo et al. [30] found a more amorphous carbonaceous structure for some chars from torrefied samples, which explained the higher gasification reactivity of chars from torrefied samples compared to chars from raw fuels when them were pyrolyzed at $1000{ }^{\circ} \mathrm{C}$.

Differences in reactivity between biomass samples have also been described in previous works and they are commonly attributed to the presence of catalytic alkaline ( $\mathrm{Na}, \mathrm{K})$ and alkaline-earth $(\mathrm{Ca}, \mathrm{Mg})$ metals $(\mathrm{AAEM})$ or gasification reaction inhibitors $(\mathrm{Si}, \mathrm{P})$ in the chars, which may have a key influence on both the gasification rate and product distribution $[11,15,31]$. It has also been claimed that the presence of such inorganic elements has more influence on the gasification rate than the surface area or the sample's morphological structure [32]. K tends to be encapsulated by P and Si with conversion, and in that case would be unable to act as a catalyst [12]. These effects are especially noticeable at low and intermediate gasification temperatures $\left(\leq 900^{\circ} \mathrm{C}\right)$, since these compounds are volatilized at higher temperatures [33].

Table 2 shows the contents of inorganic elements present in the mineral matter of the biomass samples studied. In relation to the content of inorganic elements, the two 
samples that showed the lowest reactivity values, MIS and PKS, are characterized by a very high $\mathrm{SiO}_{2}$ content (>66 wt.\%). Silicon $(\mathrm{Si})$ has been widely claimed to have an inhibiting effect on the gasification process. Dupont et al. [14] also found in their work very low reactivity values for a miscanthus sample containing high amounts of silicon. Sample SG contains a considerable amount of Si, but also a significant amount of K. Samples CHE, CH and PINT are characterized because they present a high content of $\mathrm{CaO}$ (>37 wt.\%). However, samples $\mathrm{CD}$ and $\mathrm{CS}$ are characterized because $\mathrm{K}_{2} \mathrm{O}$ (>35 wt.\%) is their main constituent. Sample OS contains a large amount of K, but also a significant amount of Ca. Samples GP and PCL contain a large amount of K, but also a high amount of Si. Finally, sample AS contains a large amount of K, but also a considerable amount of $\mathrm{Al}$.

Several equations can be found in literature considering the AAEM and silicon contents of fuels in order to provide operational information about their slagging or fouling tendency or ash acidity. These equations referred to under the labels alkali index (AI), total alkali (TA) content or base/acid ( $\left.\mathrm{R}_{\mathrm{b} / \mathrm{a}}\right)$ and silicon/alumina (S/A) ratios, as well as slagging $\left(\mathrm{R}_{\mathrm{s}}\right)$ and fouling $\left(\mathrm{F}, \mathrm{F}_{\mathrm{u}}, \mathrm{H}, \mathrm{I}\right)$ indexes $[3,28,34]$. In the present work, different indexes have been used to try to explain the experimental results, and the relevant relationships detected are shown in Fig. 6.

Figs. 6(b) and 6(c) clearly show the negative effects of the ( $\mathrm{Si}+\mathrm{P})$ and $\mathrm{Ca}$ contents, respectively, upon reactivity, when samples with very high values of these elements are considered. The inhibiting effect of silicon and phosphorus on the gasification reaction has been reported previously $[14,35]$. However, no catalytic effect of Ca was detected in the present work, although some catalytic effect of this metal $(\mathrm{K}>\mathrm{Na}>\mathrm{Ca})$ has been reported in a previous study [36]. 
The best index for explaining the biomass reactivity revealed in the experimental data of the present work is the ratio $\left(\mathrm{K}_{2} \mathrm{O}+\mathrm{Na}_{2} \mathrm{O}+\mathrm{MgO}\right) /\left(\mathrm{SiO}_{2}+\mathrm{P}_{2} \mathrm{O}_{5}+\mathrm{Al}_{2} \mathrm{O}_{3}+\mathrm{CaO}\right)$, as presented in Fig. 6(d), which shows the relationship between this index and the reactivity at $900{ }^{\circ} \mathrm{C}$. A linear tendency can be seen in the samples studied, except in the case of AS, PCL and OS, which showed lower reactivities. These three samples are characterized by a high $\mathrm{K}$ content, although they also contain significant amounts of other elements ( $\mathrm{Si}$, $\mathrm{Ca}, \mathrm{Al})$. Zhang et al. [31] concluded that the maximum gasification reactivity of biomass chars is mainly due to the catalytic effect of $\mathrm{K}$, but that the activity of $\mathrm{K}$ can be completely dismissed when $\mathrm{Si}$ is present in significant amounts. It is also worth mentioning that these three samples are characterized by a very low ash content. In general, therefore, the reactivities of the studied biomasses can be explained by the previous index, and the results have indicated positive effects of $\mathrm{K}, \mathrm{Na}$ and $\mathrm{Mg}$, but negative effects of $\mathrm{Si}, \mathrm{P}, \mathrm{Al}$ and $\mathrm{Ca}$. The catalytic effect of $\mathrm{K}$ has been the most commonly referred to in the literature, as it is the most active species in char gasification [14,31,35-37].

It follows that MIS and PKS have a very low index due to their extremely high Si content, and this would explain their very low reactivity. CHE has a very low index due to its very high $\mathrm{Ca}$ and considerable $\mathrm{Si}$, contents. This, together with its low content in catalytic elements, explains its low reactivity. SG, $\mathrm{CH}$, PINT and GP present medium index values due to their significant $(\mathrm{K}+\mathrm{Mg}+\mathrm{Na})$ content, and although they have relatively high $(\mathrm{Ca}+\mathrm{Si})$ content, the ratio in Fig. 6(d) is intermediate. Moreover, most of them have a medium to high ash content. In the case of PINT, the positive effect of catalytic elements on reactivity is shown in spite of its low ash content, which could be explained by the beneficial effect of the torrefaction process on the reactivity, as 
mentioned above. Finally, CS and CD present high index values because they mainly contain $\mathrm{K}$, with high amounts of Mg. However, the AS, OS and PCL samples present an intermediate index, with significant $\mathrm{K}$ contents, but very low reactivities, possibly due to their very low ash content. It seems therefore that in the case of these biomasses the catalytic effect of the mineral elements is not the main gasification mechanism. From the results of this study, it can be deduced that, together with the intrinsic content in possible catalytic $(\mathrm{K}, \mathrm{Na}, \mathrm{Mg})$ and inhibiting $(\mathrm{Si}, \mathrm{P}, \mathrm{Al}, \mathrm{Ca})$ elements, the ash content of the biomass is a key parameter that may determine the gasification reactivity. This has also shown that a certain ash content value in the biomass sample can be required to have a positive catalytic effect on reactivity.

\subsection{Effect of the oxidizing agent concentration on char reactivity}

The effect of the oxidizing agent concentration on reactivity at $900{ }^{\circ} \mathrm{C}$ was also studied. To this end, gasification tests using gas flows with percentages of steam ranging from 10 to $50 \%$ were performed. The relationship between the reaction rate constant and the reaction order is described by means of Eq. (15):

$k=k^{\prime} \cdot C_{H_{2} O}^{n}$

where $k$ is the reaction rate constant calculated from the RPM method, $k^{\prime}$ is a constant, $n$ is the reaction order with respect to steam partial pressure, and $\mathrm{C}_{\mathrm{H}_{2} \mathrm{O}}$ is the concentration of steam in the gas flow. If the Eq. (15) is linearized, $\ln k v s . \ln C_{H 2 O}$ can be plotted (Fig. 7) and the reaction order with respect to the steam obtained from its slope. In the present work, the reaction order was calculated for three chars, CS, SG and CHE, which are representative of fast-, medium- and slow-kinetics samples, respectively. The increase in steam concentration during the isothermal gasification caused an increase in 
the reactivity of the three studied chars, since raising the steam partial pressure would increase the conversion. Steam molecules would be adsorbed to the active sites on char surface to facilitate the steam-carbon reactions [38]. The reaction orders obtained were the following: 0.17 for CHE, 0.42 for SG and 0.80 for CS. Thus, these values decreased as the gasification rate and reactivity decreased. Barrio et al. [39] reported reaction orders with respect to steam partial pressure around 0.5-0.6 for wood chars (birch and beech). Reaction order values of 0.5-0.6 for grapefruit char were reported by MarquezMontesinos et al. [36]. Lopez et al. [40] obtained a reaction order with respect to steam of 0.34 for pinewood sawdust. Matsumoto et al. [41] obtained a reaction order with respect to steam of 0.22 for Japanese cedar char, indicating very low reactivity of this biomass. A reaction order with respect to steam of 0.77 was found by Roh et al. [42] for pine-nut shell gasification. Therefore, reaction order of biomass char gasification significantly differs from a study to another for different biomass sources. In Di Blasi's review on gasification rates of lignocellulosic chars [32], steam char gasification reaction order varied between between 0.4 and 1 . Therefore, the reaction orders determined in the present work are in agreement with those reported in literature for biomass samples, and they are in concordance with the char reactivity.

\section{Conclusions}

A data set of kinetic parameters for the steam gasification of twelve biomasses was collected by fitting experimental data to three predictive models (VM, GM and RPM). The most accurate model for explaining the conversion was RPM, which provided $E_{a}$ values of 59-196 kJ mol${ }^{-1}$. The samples were classified into five reactivity groups: fast (CD, CS), medium-fast (CH, PINT, GP), medium (OS, PCL, SG), slow-medium (AS, 
CHE) and slow (MIS, PKS). It was found that the ash inorganic element composition influenced gasification reactivity (i.e., the catalytic effect of $\mathrm{K}, \mathrm{Na}$ and $\mathrm{Mg}$ and inhibiting effect of $\mathrm{Si}, \mathrm{P}$ and $\mathrm{Ca}$ ), although the biomass ash content was also a key parameter.

\section{Acknowledgements}

This work has received financial support from the Spanish MINECO (ENE2014-53515P), cofinanced by the European Regional Development Fund (ERDF), and from the Gobierno del Principado de Asturias (PCTI-GRUPIN14-079). M.P. González-Vázquez also acknowledges a fellowship awarded by the Spanish MINECO (FPI program), cofinanced by the European Social Fund.

\section{References}

[1] Thomsen TP, Sárossy Z, Gøbel B, Stoholm P, Ahrenfeldt J, Frandsen FJ, Henriksen

UB. Low temperature circulating fluidized bed gasification and co-gasification of municipal sewage sludge. Part 1: Process performance and gas product characterization. Waste Manage 2017;66:123-33.

[2] Molino A, Chianese S, Musmarra D. Biomass gasification technology: The state of the art overview. J Energy Chem 2016;25:10-25.

[3] Hernández JJ, Lapuerta M, Monedero E. Characterisation of residual char from biomass gasification: effect of the gasifier operating conditions. J Clean Prod 2016;138:83-93.

[4] Fermoso J, Stevanov C, Moghtaderi B, Arias B, Pevida C, Plaza MG, Rubiera F, Pis JJ. High-pressure gasification reactivity of biomass chars produced at different 
temperatures. J Anal Appl Pyrolysis 2009;85:287-93.

[5] Bocci E, Sisinni M, Moneti M, Vecchione L, Di Carlo A, Villarini M. State of art of small scale biomass gasification power systems: A review of the different typologies. Energy Procedia 2014;45:247-56.

[6] $\mathrm{Ku} \mathrm{X}$, Jin $\mathrm{H}$, Lin J. Comparison of gasification performances between raw and torrefied biomasses in an air-blown fluidized-bed gasifier. Chem Eng Sci $2017 ; 168: 235-49$.

[7] Sbirrazzuoli N, Vincent L, Mija A, Guigo N. Integral, differential and advanced isoconversional methods. Complex mechanisms and isothermal predicted conversiontime curves. Chemom Intell Lab Syst 2009;96:219-26.

[8] Šimon P. Isoconversional Methods Fundamentals, meaning and application. J Therm Anal Calorim 2004;76:123-32.

[9] Álvarez A, Pizarro C, García R, Bueno JL, Lavín AG. Determination of kinetic parameters for biomass combustion. Bioresour Technol 2016;216:36-43. [10] Mabuda AI, Mamphweli NS, Meyer EL. Model free kinetic analysis of biomass/sorbent blends for gasification purposes. Renew Sustain Energy Rev 2016;53:1656-64.

[11] Fermoso J, Gil MV, Pevida C, Pis JJ, Rubiera F. Kinetic models comparison for non-isothermal steam gasification of coal-biomass blend chars. Chem Eng J 2010;161:276-84.

[12] Le CD, Kolaczkowski ST. Steam gasification of a refuse derived char: Reactivity and kinetics. Chem Eng Res Des 2015;102:389-98.

[13] Zhai M, Zhang Y, Dong P, Liu P. Characteristics of rice husk char gasification with steam. Fuel 2015;158:42-9. 
[14] Dupont C, Jacob S, Marrkchy KO, Hognon C, Grateau M, Labalette F, Perez DDS. How inorganic elements of biomass influence char steam gasification kinetics. Energy 2016;109:430-5.

[15] Obernberger I, Brunner T, Bärnthaler G. Chemical properties of solid biofuelssignificance and impact. Biomass Bioenerg 2006;30:973-82.

[16] Telmo C, Lousada J, Moreira N. Proximate analysis, backwards stepwise regression between gross calorific value, ultimate and chemical analysis of wood. Bioresour Technol 2010;101:3808-15.

[17] Arenillas A, García R, Sun C, Snape C, Moreno AH, Rubiera F, Pis JJ. Use of nitrogen stable isotope analysis to understand char nitrogen evolution during the fluidized-bed co-combustion of coal and sewage sludge. Energy Fuels 2005;19:485-8. [18] Paviet F, Bals O, Antonini G. The effects of diffusional resistance on wood char gasification. Process Saf Environ Prot 2008;86:131-40.

[19] Lu GQ, Do DD. Comparison of structural models char gasification. Carbon $1994 ; 32: 247-63$.

[20] Ishida M, Wen CY. Comparison of zone-reaction model and unreacted-core shrinking model in solid-gas reactions - I. Isothermal analysis. Chem Eng Sci 1971;26:1031-41.

[21] Szekely J, Evans JW. A structure model for gas solid reactions with a moving boundary-II: The effect of grain size, porosity and temperature on the reaction of porous pellets. Chem Eng Sci 1970;26:1901-13.

[22] Bhatia SK, Perlmutter DD. A random pore model for fluid-solid reactions: I. Isothermal, kinetic control. AIChE J 1980;26:379-86.

[23] Fermoso J, Arias B, Pevida C, Plaza MG, Rubiera F, Pis JJ. Kinetic models 
comparison for steam gasification of different nature fuel chars. J Therm Anal Calorim 2008;91:779-86.

[24] Fermoso J, Gil MV, García S, Pevida C, Pis JJ, Rubiera F. Kinetic parameters and reactivity for the steam gasification of coal chars obtained under different pyrolysis temperatures and pressures. Energy Fuels 2011;25:3574-80.

[25] Xu C, Hu S, Xiang J, Yang H, Sun L, Su S, Wang B, Chen Q, He L. Kinetic models comparison for steam gasification of coal/biomass blend chars. Bioresour Technol 2014;171:253-9.

[26] Morin M, Pécate S, Hémati M. Experimental study and modelling of the kinetic of biomass char gasification in a fluidized bed reactor. Chem Eng Res Design $2018 ; 131: 488-505$

[27] Fermoso J, Gil MV, Borrego AG, Pevida C, Pis JJ, Rubiera F. Effect of the pressure and temperature of devolatilization on the morphology and steam gasification reactivity of coal chars. Energy Fuels 2010;24:5586-95.

[28] López-González D, Fernandez-Lopez M, Valverde JL, Sanchez-Silva L.

Gasification of lignocellulosic biomass char obtained from pyrolysis: Kinetic and evolved gas analyses. Energy 2014;71:456-67.

[29] Zhang Y, Geng P, Liu R. Synergistic combination of biomass torrefaction and cogasification: Reactivity studies. Bioresour Technol 2017;245:225-33.

[30] Guo P, Saw WL, van Eyk PJ, Stechel EB, de Nys R, Ashman PJ, Nathan GJ.

Gasification Reactivity and Physicochemical Properties of the Chars from Raw and Torrefied Wood, Grape Marc, and Macroalgae. Energy Fuels 2017;31:2246-59.

[31] Zhang Y, Ashizawa M, Kajitani S, Miura K. Proposal of a semi-empirical kinetic model to reconcile with gasification reactivity profiles of biomass chars. Fuel 
$2008 ; 87: 475-81$.

[32] Di Blasi C. Combustion and gasification rates of lignocellulosic chars. Prog Energy Combust Sci 2009;35:121-40.

[33] Ochoa J, Cassanello MC, Bonelli PR, Cukierman AL. $\mathrm{CO}_{2}$ gasification of Argentinean coal chars: A kinetic characterization. Fuel Process Technol 2001;74:16176.

[34] García R, Pizarro C, Álvarez A, Lavín AG, Bueno JL. Study of biomass combustion wastes. Fuel 2015;148:152-9.

[35] Yip K, Tian F, Hayashi J, Wu H. Effect of Alkali and Alkaline Earth Metallic Species on Biochar Reactivity and Syngas Compositions during Steam Gasification. Energy Fuels 2010;24:173-81.

[36] Marquez-Montesinos F, Cordero T, Rodríguez-Mirasol J, Rodríguez JJ. $\mathrm{CO}_{2}$ and steam gasification of a grapefruit skin char. Fuel 2002;81:423-9.

[37] Dupont C, Nocquet T, Da Costa JA, Verne-Tournon C. Kinetic modelling of steam gasification of various woody biomass chars: Influence of inorganic elements. Bioresour Technol 2011;102:9743-8.

[38] Wang F, Zeng X, Wang Y, Yu J, Xu G. Characterization of coal char gasification with steam in a micro-fluidized bed reaction analyzer. Fuel Process Technol $2016 ; 141: 2-8$.

[39] Barrio M, Gøbel B, Risnes H, Henriksen U, Hustad JE, Sørensen LH. Steam gasification of wood char and the effect of hydrogen inhibition on the chemical kinetics. In: Bridgwater AV, editor. Progress in Thermochemical Biomass Conversion, Oxford: Blackwell Science Ltd; 2001, p 32-46.

[40] Lopez G, Alvarez J, Amutio M, Arregi A, Bilbao J, Olazar M. Assessment of 
steam gasification kinetics of the char from lignocellulosic biomass in a conical spouted bed reactor. Energy 2016;107:493-501.

[41] Matsumoto K, Takeno K, Ichinose T, Ogi T, Nakanishi M. Gasification reaction kinetics on biomass char obtained as a by-product of gasification in an entrained-flow gasifier with steam and oxygen at 900-1000 ${ }^{\circ} \mathrm{C}$. Fuel 2009;88:519-27.

[42] Roh SA, Son SR, Kim SD, Lee WJ, Lee YK. Steam Gasification Characteristics of a Pine-Nut Shell in a Thermobalance and a Fluidized Bed Reactor. Key Engineering Materials 2005;277-279:637-43. 


\section{Figure captions}

Fig. 1. Images of the untreated biomass samples: a) AS; b) $\mathrm{CD}$; c) $\mathrm{CH}$; d) $\mathrm{CHE}$; e) $\mathrm{CS}$; f) GP; g) MIS; h) OS; i) PCL; j) PINT; k) PKS; and 1) SG.

Fig. 2. Linear fitting obtained for the VM, GM and RPM $\Psi_{a d j}$ models for samples AS (a, $b, c)$ and OS (d, e, f).

Fig. 3. Linear fitting obtained for the VM, GM and RPM $\Psi_{a d j}$ models for samples PCL (a, $b, c)$ and PKS (d, e, f).

Fig. 4. Arrhenius plots using the VM, GM and RPM $\Psi_{a d j}$ models for: a) AS, b) OS, c) PCL, and d) PKS.

Fig. 5. Experimental conversion data and their comparison with the values predicted by the VM, GM and RPM $\Psi_{a d j}$ kinetic models for AS (a), OS (b), PCL (c) and PKS (d), as well as for all the studied samples at $900{ }^{\circ} \mathrm{C}$ using the $\mathrm{RPM} \Psi_{a d j}(\mathrm{e})$.

Fig. 6. Reactivity at $900{ }^{\circ} \mathrm{C}$ (a) and effect of the ash inorganic elements on the $R$ index (b, c and d).

Fig. 7. Reactivity of chars CS, SG and CHE as a function of the steam concentration. 


\section{Tables}

\begin{tabular}{|c|c|c|c|c|c|c|c|c|c|c|}
\hline \multirow{3}{*}{ Sample } & \multirow{2}{*}{\multicolumn{5}{|c|}{$\begin{array}{l}\text { Ultimate analysis } \\
\text { (wt.\%, db) }\end{array}$}} & \multicolumn{4}{|c|}{ Proximate analysis } & \multirow{3}{*}{$\begin{array}{l}\text { HHV } \\
\left(\mathrm{MJ} \mathrm{kg}^{-1}, \mathrm{db}\right)\end{array}$} \\
\hline & & & & & & \multirow{2}{*}{$\begin{array}{l}\text { (wt.\%) } \\
\text { MC }\end{array}$} & \multicolumn{3}{|c|}{ (wt.\%, daf) } & \\
\hline & $\mathbf{C}$ & $\mathbf{N}$ & $\mathbf{H}$ & $\mathbf{S}$ & $\mathbf{O}^{\mathrm{a}}$ & & Ash & VM & $\mathbf{F C}^{\mathrm{a}}$ & \\
\hline $\mathbf{A S}$ & 49.4 & 0.3 & 5.9 & 0.05 & 42.85 & 6.5 & 1.5 & 78.9 & 19.6 & 19.565 \\
\hline CD & 48.0 & 3.7 & 5.7 & 0.27 & 33.73 & 7.2 & 8.6 & 70.2 & 21.2 & 19.389 \\
\hline CH & 49.6 & 3.0 & 6.1 & 0.22 & 36.88 & 8.4 & 4.2 & 79.2 & 16.6 & 20.189 \\
\hline CHE & 50.2 & 0.3 & 5.6 & 0.01 & 43.39 & 8.4 & 0.5 & 81.2 & 18.3 & 19.109 \\
\hline CS & 48.0 & 2.7 & 5.9 & 0.21 & 35.29 & 6.7 & 7.9 & 70.4 & 21.7 & 19.067 \\
\hline GP & 45.5 & 1.8 & 5.1 & 0.17 & 34.73 & 11.6 & 12.7 & 67.6 & 19.7 & 18.682 \\
\hline MIS & 48.0 & 0.4 & 5.8 & 0.11 & 36.49 & 5.6 & 9.2 & 77.6 & 13.2 & 18.682 \\
\hline OS & 51.2 & 0.3 & 6.0 & 0.03 & 41.87 & 4.3 & 0.6 & 81.5 & 17.9 & 20.511 \\
\hline PCL & 52.9 & 0.4 & 6.1 & 0.03 & 39.47 & 10.1 & 1.1 & 76.5 & 22.4 & 20.976 \\
\hline PINT & 54.5 & 0.4 & 5.7 & 0.02 & 38.98 & 6.4 & 0.4 & 78.6 & 21.0 & 21.568 \\
\hline PKS & 52.3 & 0.6 & 6.2 & 0.05 & 39.05 & 9.4 & 1.8 & 78.4 & 19.8 & 20.767 \\
\hline SG & 47.8 & 0.8 & 5.7 & 0.10 & 41.00 & 12.4 & 4.6 & 79.7 & 15.7 & 18.970 \\
\hline
\end{tabular}

db: dry basis; daf: dry ash-free basis; MC: moisture content; VM: volatile matter; FC: fixed carbon; HHV: higher heating value

${ }^{a}$ Determined by difference.

Table 1. Ultimate, proximate and calorific value analyses for the studied biomass samples. 


\begin{tabular}{|c|c|c|c|c|c|c|c|c|c|c|c|}
\hline \multirow{2}{*}{ Sample } & \multicolumn{11}{|c|}{ Elemental composition as metallic oxides $\left(\mathbf{w t} . \%, \mathbf{d b}^{\mathrm{a}}\right)$} \\
\hline & $\mathrm{Na}_{2} \mathrm{O}$ & MgO & $\mathbf{A l}_{2} \mathbf{O}_{3}$ & $\mathrm{SiO}_{2}$ & $\mathbf{P}_{2} \mathbf{O}_{5}$ & $\mathbf{K}_{2} \mathbf{O}$ & $\mathrm{CaO}$ & $\mathrm{TiO}_{2}$ & $\mathrm{Fe}_{2} \mathrm{O}_{3}$ & $\mathrm{SO}_{3}$ & MnO \\
\hline $\mathbf{A S}$ & 0.8 & 2.6 & 17.4 & 7.0 & 3.2 & 36.7 & 12.3 & 0.1 & 1.8 & 0.7 & 0.1 \\
\hline CD & 0.3 & 8.9 & 1.4 & 2.3 & 2.6 & 35.0 & 14.3 & 0.2 & 1.2 & 0.3 & 0.1 \\
\hline $\mathrm{CH}$ & 0.9 & 8.4 & 1.0 & 2.4 & 2.6 & 19.4 & 38.8 & 0.1 & 1.1 & 3.6 & 0.2 \\
\hline CHE & 0.6 & 5.9 & 3.4 & 17.6 & 3.1 & 7.4 & 55.3 & 0.3 & 2.2 & 1.8 & N/D \\
\hline CS & 0.0 & 8.8 & 2.1 & 16.6 & 16.5 & 45.1 & 6.3 & 0.2 & 1.2 & 2.0 & 0.1 \\
\hline GP & 3.4 & 3.4 & 6.5 & 29.8 & 4.4 & 31.9 & 10.8 & 0.3 & 3.0 & 1.5 & 0.1 \\
\hline MIS & 1.8 & 3.1 & 2.4 & 72.2 & 1.0 & 8.4 & 6.8 & 0.1 & 1.5 & 0.1 & 0.1 \\
\hline OS & 1.2 & 2.9 & 1.1 & 4.9 & 4.0 & 37.9 & 19.0 & 0.1 & 1.6 & 1.7 & 0.1 \\
\hline PCL & 1.8 & 8.8 & 3.7 & 19.7 & 6.0 & 34.4 & 8.3 & 0.1 & 0.6 & 0.0 & 0.2 \\
\hline PINT & 1.2 & 11.1 & 3.0 & 19.7 & 3.7 & 16.3 & 36.7 & 0.2 & 3.2 & 2.9 & $\mathrm{~N} / \mathrm{D}$ \\
\hline PKS & 1.4 & 5.5 & 0.8 & 66.4 & 1.9 & 18.3 & 3.5 & 0.0 & 0.5 & 0.1 & 0.1 \\
\hline SG & 1.4 & 6.4 & 0.8 & 44.2 & 7.4 & 20.7 & 14.1 & 0.0 & 0.6 & 2.6 & 0.1 \\
\hline
\end{tabular}

db: dry basis.

Table 2. Ash elemental composition data obtained by XRF for the studied biomass samples. 


\begin{tabular}{|c|c|c|c|c|c|c|c|c|c|c|c|c|c|c|}
\hline \multirow{2}{*}{ Sample } & \multicolumn{3}{|l|}{ VM } & \multicolumn{3}{|l|}{ GM } & \multicolumn{4}{|c|}{$\mathbf{R P M} \Psi_{\exp }$} & \multicolumn{4}{|c|}{$\mathbf{R P M} \Psi a d j$} \\
\hline & $E_{a}$ & $k_{0}$ & $\operatorname{Dev}(X)$ & $E_{a}$ & $k_{0}$ & $\operatorname{Dev}(X)$ & $E_{a}$ & $k_{0}$ & $\Psi_{\exp }$ & $\operatorname{Dev}(X)$ & $E_{a}$ & $k_{0}$ & $\Psi_{\text {adj }}$ & $\operatorname{Dev}(X)$ \\
\hline $\mathbf{A S}$ & 85.9 & $3.26 \mathrm{E}+00$ & 5.43 & 85.1 & $2.30 \mathrm{E}+00$ & 3.19 & 85.0 & $1.93 \mathrm{E}+00$ & 2.09 & 2.86 & 85.2 & $2.14 \mathrm{E}+00$ & 2.15 & 2.85 \\
\hline CD & 57.2 & $4.23 \mathrm{E}+00$ & 13.99 & 58.0 & $3.60 \mathrm{E}+00$ & 10.59 & 58.4 & $2.14 \mathrm{E}+00$ & 8.03 & 7.61 & 58.6 & $1.36 \mathrm{E}+00$ & 27.9 & 7.17 \\
\hline CH & 168.2 & $2.54 \mathrm{E}+04$ & 7.25 & 167.9 & $1.89 \mathrm{E}+04$ & 6.72 & 167.9 & $1.49 \mathrm{E}+04$ & 2.73 & 7.54 & 168.0 & $1.92 \mathrm{E}+04$ & 0.93 & 6.52 \\
\hline CHE & 157.5 & $5.12 \mathrm{E}+03$ & 4.13 & 157.0 & $3.69 \mathrm{E}+03$ & 4.78 & 156.9 & $3.03 \mathrm{E}+03$ & 2.27 & 5.75 & 157.3 & $4.47 \mathrm{E}+03$ & 0.32 & 3.77 \\
\hline CS & 170.9 & $1.57 \mathrm{E}+05$ & 7.29 & 170.4 & $1.15 \mathrm{E}+05$ & 4.41 & 162.1 & $3.18 \mathrm{E}+04$ & 3.87 & 6.34 & 170.5 & $1.00 \mathrm{E}+05$ & 1.93 & 4.07 \\
\hline GP & 127.0 & $6.04 \mathrm{E}+02$ & 6.14 & 126.7 & $4.49 \mathrm{E}+02$ & 5.63 & 126.6 & $3.44 \mathrm{E}+02$ & 2.94 & 6.34 & 126.8 & $4.81 \mathrm{E}+02$ & 0.69 & 5.33 \\
\hline MIS & 64.5 & $1.58 \mathrm{E}-01$ & 6.76 & 64.4 & $1.22 \mathrm{E}-01$ & 3.90 & 64.4 & $1.04 \mathrm{E}-01$ & 2.04 & 3.71 & 64.4 & $1.07 \mathrm{E}-01$ & 1.83 & 3.70 \\
\hline OS & 196.1 & $3.81 \mathrm{E}+05$ & 4.52 & 195.6 & $2.77 \mathrm{E}+05$ & 3.22 & 195.6 & $2.21 \mathrm{E}+05$ & 2.70 & 3.85 & 195.7 & $2.70 \mathrm{E}+05$ & 1.21 & 3.05 \\
\hline PCL & 188.8 & $1.98 \mathrm{E}+05$ & 3.09 & 187.9 & $1.38 \mathrm{E}+05$ & 3.65 & 187.8 & $1.08 \mathrm{E}+05$ & 2.69 & 5.21 & 188.4 & $1.67 \mathrm{E}+05$ & 0.37 & 2.47 \\
\hline PINT & 180.6 & $1.31 \mathrm{E}+05$ & 6.45 & 179.6 & $8.99 \mathrm{E}+04$ & 7.11 & 179.4 & $6.84 \mathrm{E}+04$ & 2.85 & 8.07 & 180.4 & $1.20 \mathrm{E}+05$ & 0.16 & 6.39 \\
\hline PKS & 72.7 & 4.03E-01 & 6.38 & 72.6 & $3.08 \mathrm{E}-01$ & 2.19 & 72.6 & 2.63E-01 & 2.03 & 1.42 & 72.6 & $2.50 \mathrm{E}-01$ & 2.47 & 1.31 \\
\hline SG & 171.2 & $4.25 \mathrm{E}+04$ & 4.93 & 170.9 & $3.18 \mathrm{E}+04$ & 2.80 & 170.9 & $2.68 \mathrm{E}+04$ & 2.12 & 3.08 & 171.0 & $3.11 \mathrm{E}+04$ & 1.13 & 2.57 \\
\hline
\end{tabular}

Table 3. Kinetic parameters and $\operatorname{Dev}(X)$ obtained for the tested samples. $E_{a}$ is measured in $\mathrm{kJ} \mathrm{mol}^{-1}, k_{0}$ in s${ }^{-1}$ and $\operatorname{Dev}(X)$ in $\%$. 


\section{Figures}

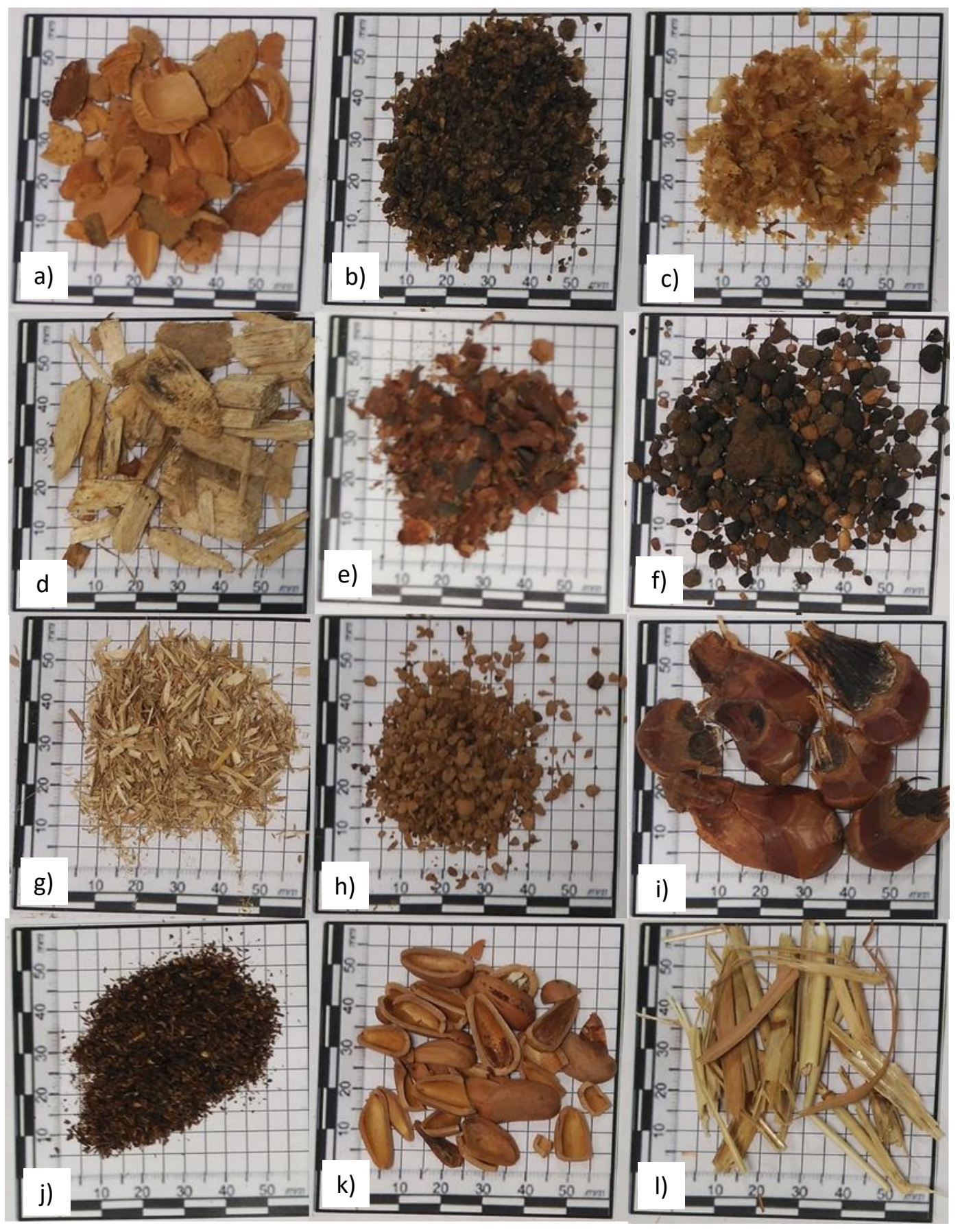

Fig. 1. Images of the untreated biomass samples: a) AS; b) $\mathrm{CD}$; c) $\mathrm{CH}$; d) $\mathrm{CHE}$; e) $\mathrm{CS}$;

f) GP; g) MIS; h) OS; i) PCL; j) PINT; k) PKS; and l) SG. 

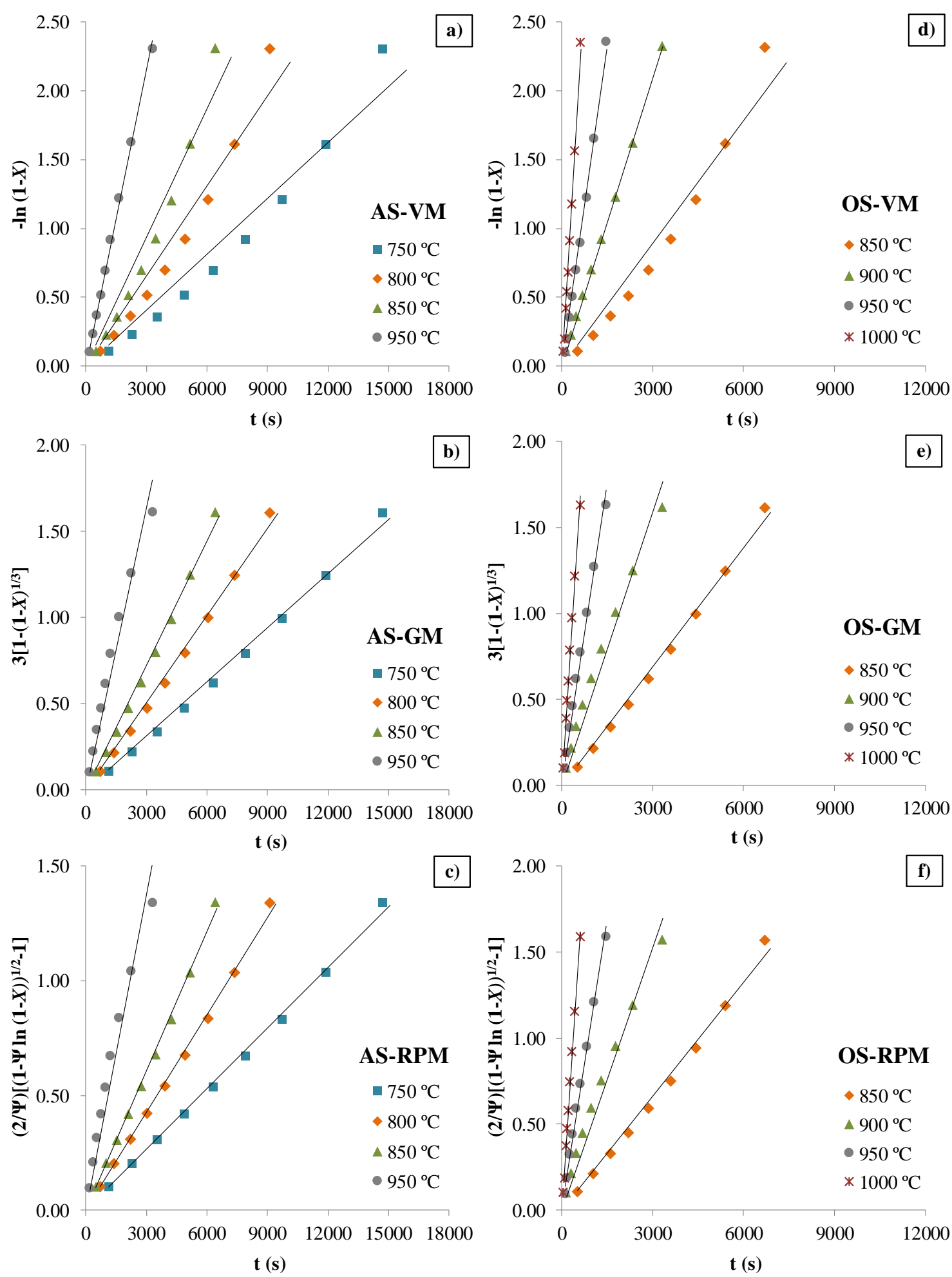

Fig. 2. Linear fittings obtained for the VM, GM and RPM $\Psi_{a d j}$ models for samples AS (a, $b, c)$ and OS (d, e, f). 

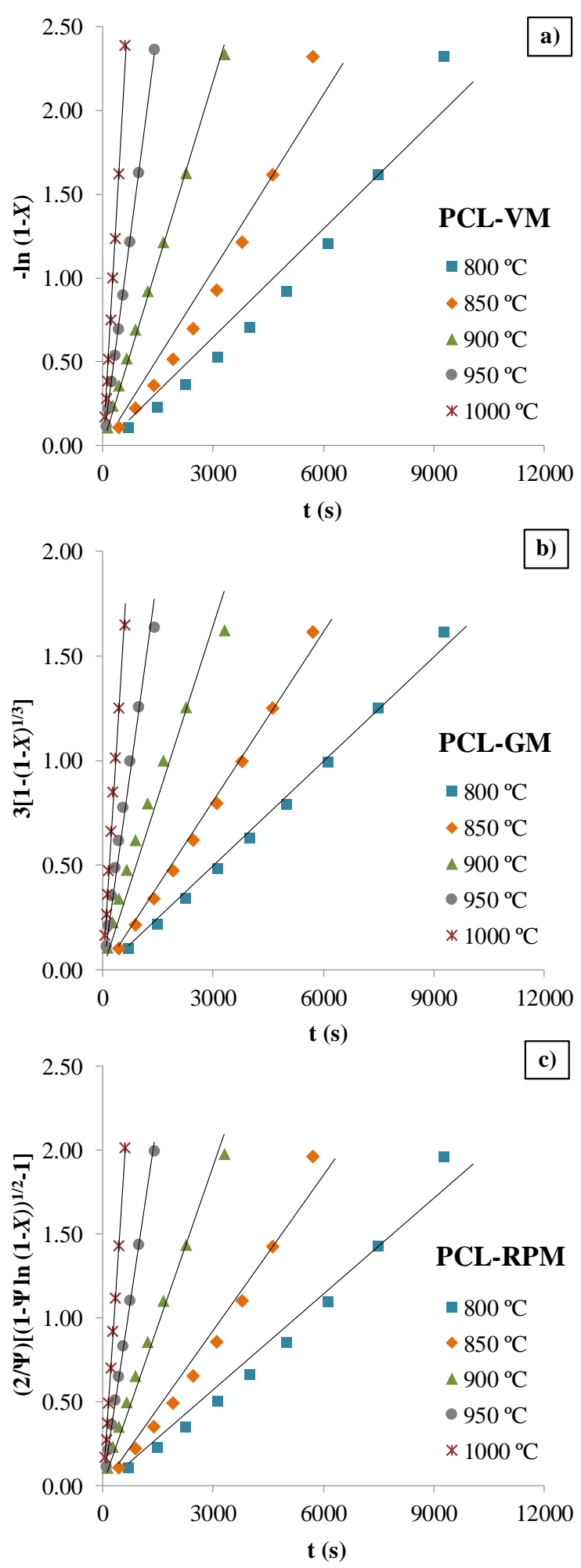

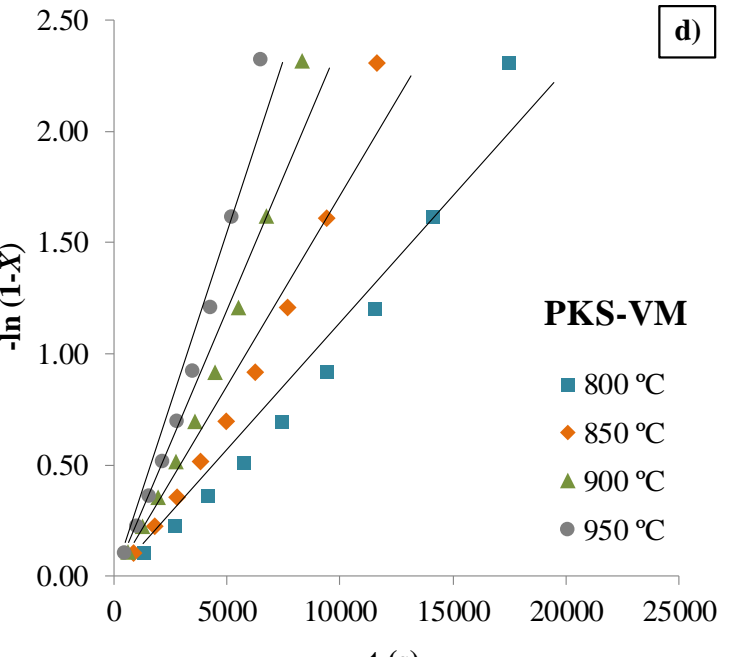

$\mathbf{t}(\mathbf{s})$

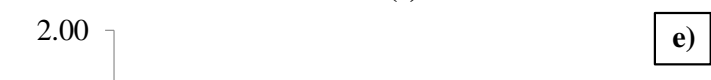

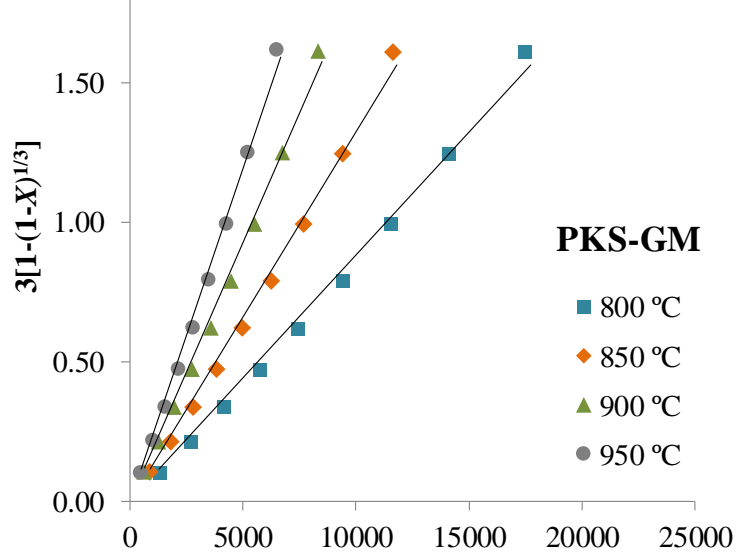

t (s)

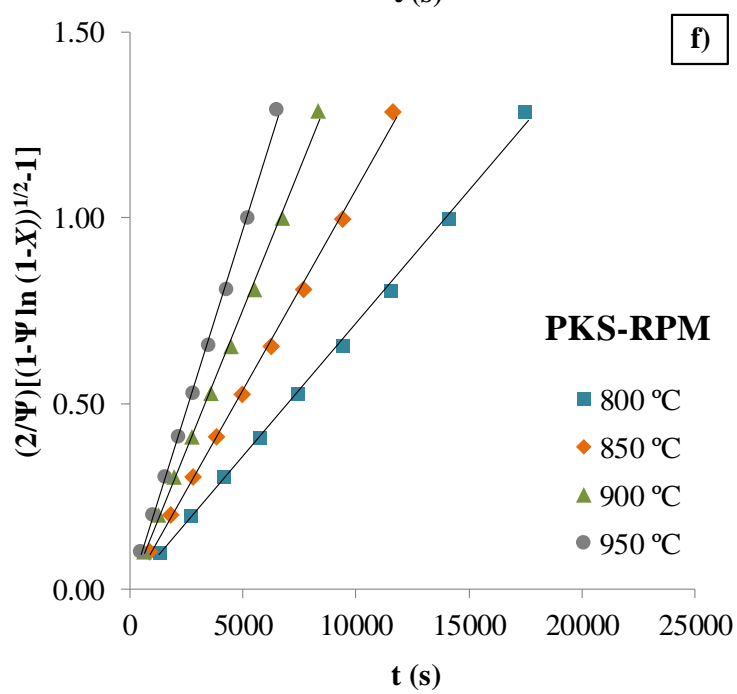

Fig. 3. Linear fitting obtained for the VM, GM and RPM $\Psi_{a d j}$ models for samples PCL (a, $\mathrm{b}, \mathrm{c})$ and PKS (d, e, f). 

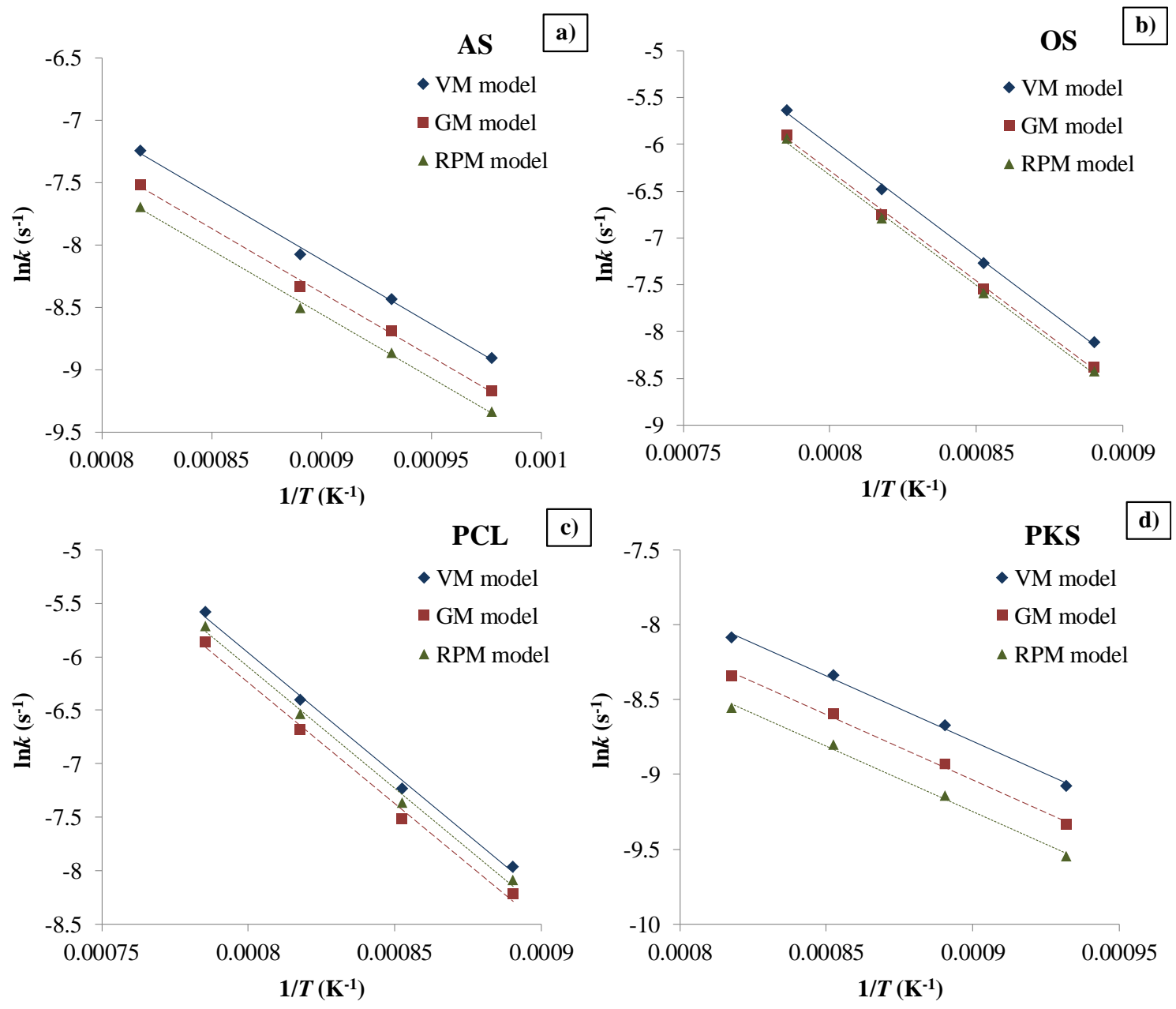

Fig. 4. Arrhenius plots using the VM, GM and RPM $\Psi_{a d j}$ models for: a) AS, b) OS, c) PCL, and d) PKS. 

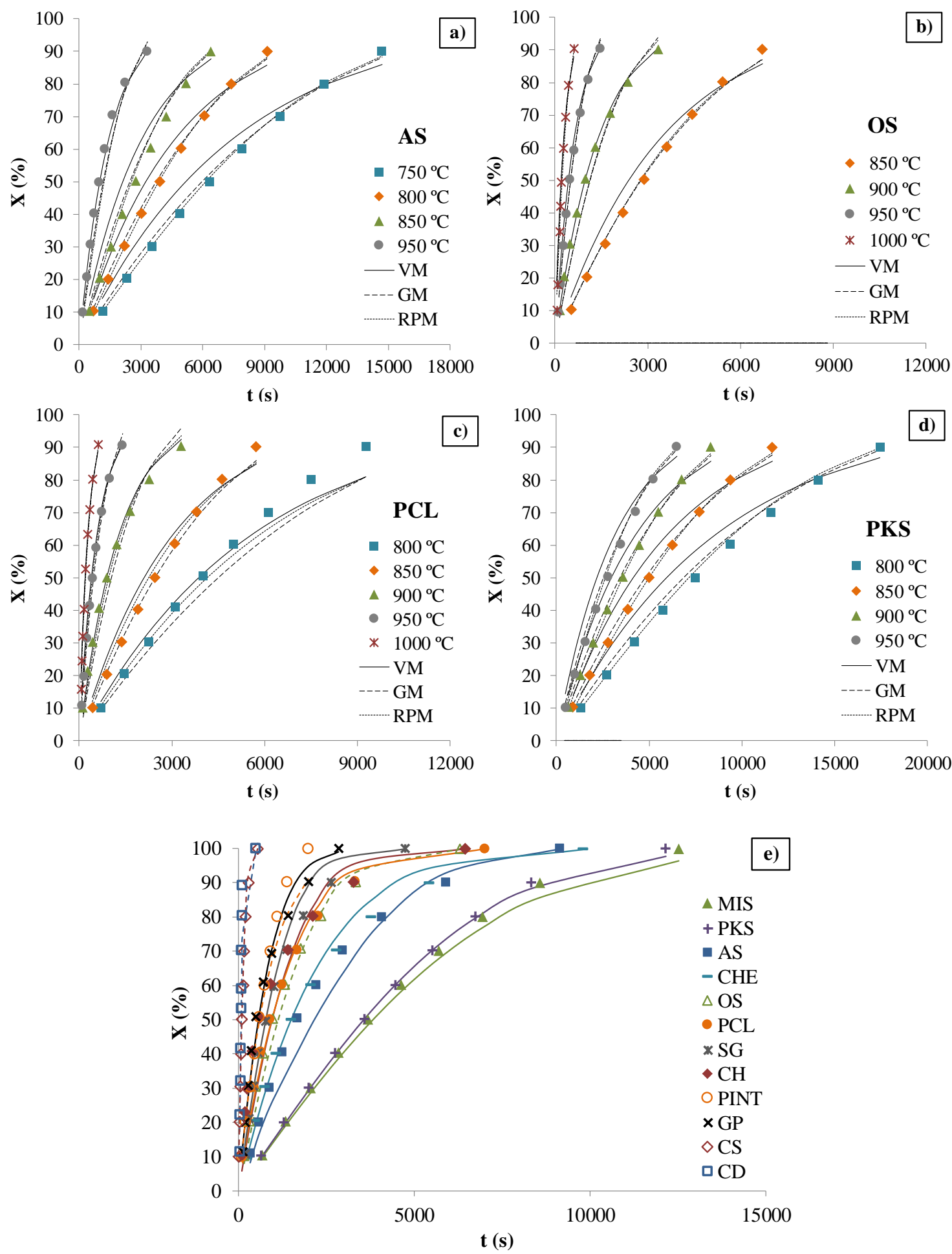

Fig. 5. Experimental conversion data and their comparison with the values predicted by the VM, GM and RPM $\Psi_{a d j}$ kinetic models for AS (a), OS (b), PCL (c) and PKS (d), as well as for all the studied samples at $900{ }^{\circ} \mathrm{C}$ using the $\mathrm{RPM} \Psi_{a d j}(\mathrm{e})$. 

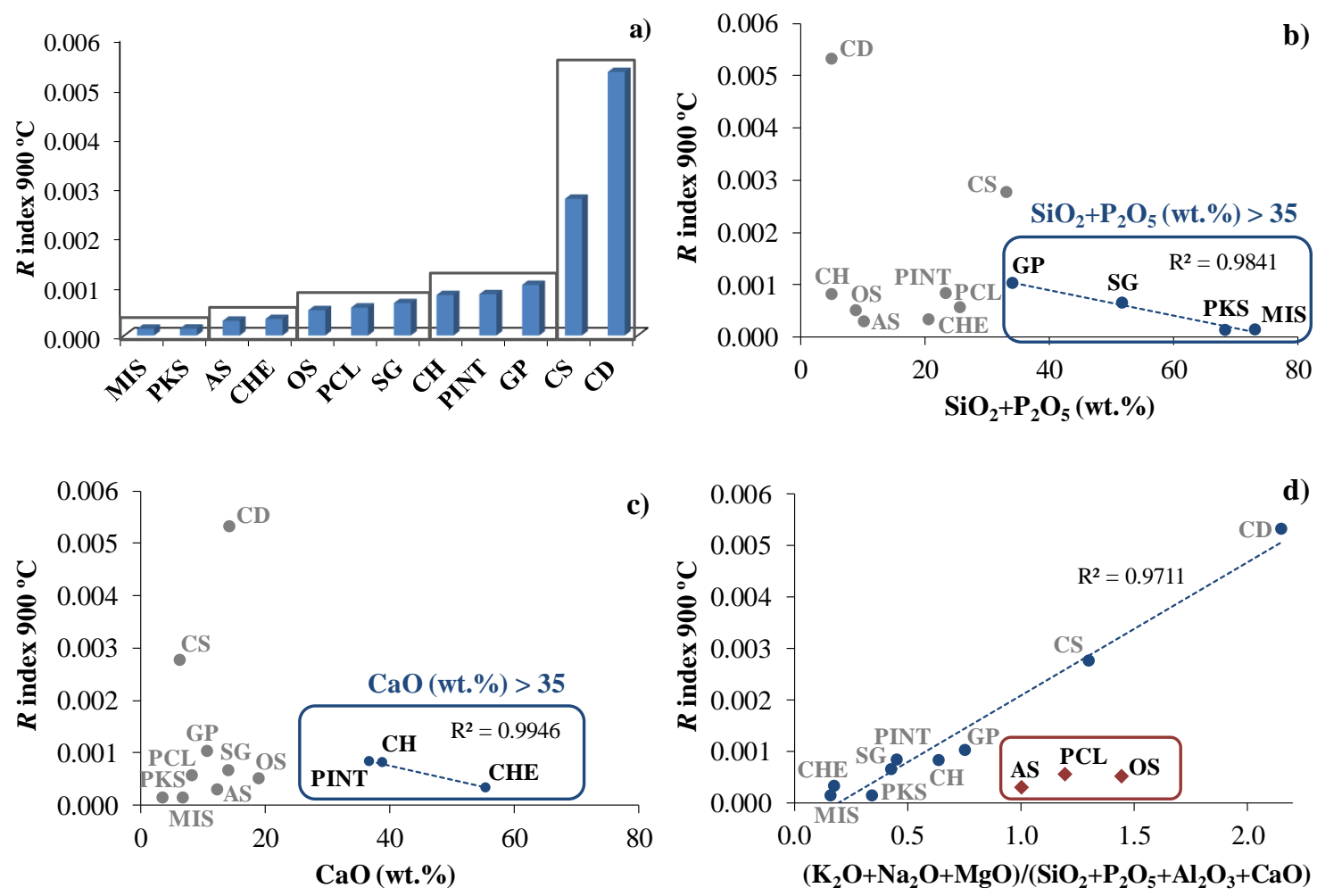

Fig. 6. Reactivity at $900{ }^{\circ} \mathrm{C}$ (a) and effect of the ash inorganic elements on the $R$ index (b, c and d). 


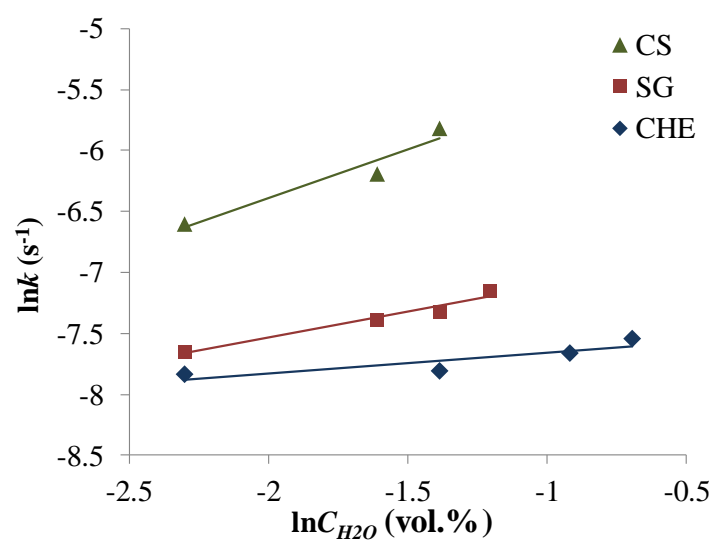

Fig. 7. Reactivity of chars CS, SG and CHE as a function of the steam concentration. 